\title{
Testing, Modeling and System Impact of Metabolic Heat Regenerated Temperature Swing Adsorption
}

\author{
Christine S. Iacomini, Aaron Powers, Matthew Lewis, and Christopher Linrud \\ Paragon Space Development Corporation, Tucson, AZ, USA \\ Glenn Waguespack \\ GeoControl Systems, Inc., Houston, TX, USA \\ Bruce Conger \\ Hamilton Sundstrand, Houston, TX, USA \\ Heather L. Paul \\ National Aeronautics and Space Administration Johnson Space Center, Houston, TX, USA
}

Copyright $(2008$ SAE International

\begin{abstract}
Metabolic heat regenerated temperature swing adsorption (MTSA) technology is being developed for removal and rejection of carbon dioxide $\left(\mathrm{CO}_{2}\right)$ and heat from a portable life support system (PLSS) to the Martian environment. Previously, hardware was built and tested to demonstrate using heat from simulated, dry ventilation loop gas to affect the temperature swing required to regenerate an adsorbent used for $\mathrm{CO}_{2}$ removal. New testing has been performed using a moist, simulated ventilation loop gas to demonstrate the effects of water condensing and freezing in the heat exchanger during adsorbent regeneration. In addition, thermal models of the adsorbent during regeneration were modified and calibrated with test data to capture the effect of the $\mathrm{CO}_{2}$ heat of desorption. Finally, MTSA impact on PLSS design was evaluated by performing thermal balances assuming a specific PLSS architecture. Results using NASA's Extravehicular Activity System Sizing Analysis Tool (EVAS_SAT), a PLSS system evaluation tool, are presented.
\end{abstract}

\section{INTRODUCTION}

Metabolic heat regenerated temperature swing adsorption (MTSA) technology is being developed for removal and rejection of carbon dioxide $\left(\mathrm{CO}_{2}\right)$ and heat from a portable life support system (PLSS) to the Martian environment. The technology is also designed to aid in ventilation loop humidity control.

The metabolically-produced $\mathrm{CO}_{2}$ present in the ventilation loop gas is collected using a $\mathrm{CO}_{2}$-selective adsorbent via temperature swing adsorption. The temperature swing is achieved through cooling using
Martian liquid $\mathrm{CO}_{2}\left(\mathrm{LCO}_{2}\right)$ and warming using heat from used ventilation loop gas.

During adsorb mode, the adsorbent is cooled via a heat exchanger using $\mathrm{LCO}_{2}$ obtained from Martian resources. Inside the heat exchanger, the coolant is expanded from liquid at moderate pressure and temperature of 90 $770 \mathrm{psi}$ and 220 - $290 \mathrm{~K}$ (depending upon storage temperature) to solid at ambient pressure $(0.8 \mathrm{kPa})$ and $\sim 150 \mathrm{~K}$. Upon isenthalpic expansion, the liquid changes to solid and immediately sublimates. The cooling power is derived from the overall phase change of stored liquid to cold, sublimated gas. The now gaseous $\mathrm{CO}_{2}$ may be used for further cooling if needed and then is exhausted to the surrounding $\mathrm{CO}_{2}$ environment.

Once the adsorbent is fully loaded, un-regenerated, warm $(-300 \mathrm{~K})$, moist ventilation loop gas directly from the user is used to heat the adsorbent via a separate condensing ice heat exchanger. The moisture in the ventilation gas condenses and initially ices since the adsorbent is $\sim 210 \mathrm{~K}$. As the bed warms, the metabolic $\mathrm{CO}_{2}$ collected during adsorb mode is desorbed to the Martian ambient. The ice eventually melts and water is collected and recycled at the habitat.

The technology has several advantageous operational considerations. 1) MTSA does not reject water to the environment and contaminate the area of which an astronaut is investigating. 2) MTSA does not require consumables brought from Earth. The $\mathrm{LCO}_{2}$ coolant can be made on Mars using the Martian atmosphere for relatively low infrastructure and energy costs [1]. This is a significant mission mass savings and reduction in risk. 3) $\mathrm{LCO}_{2}$ is not a cryogenic. It can be stored anywhere 
on the surface of Mars at moderate pressure without losses due to boil-off and for indefinite periods of time.

As MTSA technology addresses well the challenges posed by missions performed in the unique environment of Mars, with very limited accessibility from Earth, mitigating PLSS development risk is sound justification for pursing its development. Given limited resources, the development efforts have focused on critical areas with in the concept that could be "deal-breakers". Further, these efforts have been crafted to hedge on previous work and infrastructure (i.e. pre-existing test beds, demonstration hardware to achieve multiple tasks, existing models, etc.). This paper will describe such efforts in further investigating and developing MTSA technology.

\section{BACKGROUND}

Hardware (a.k.a. the "Demonstrator") was designed, built and tested to demonstrate feasibility of the MTSA concept [3]. Liquid $\mathrm{CO}_{2}$ stored at room temperature was used to cool Molsiv Adsorbents 13X 8x12 (also known as $\mathrm{NaX}$ zeolite) to $210 \mathrm{~K}$ via a heat exchanger. Warm, dry, simulated ventilation loop gas at $40 \mathrm{kPa}$ was used to achieve an adsorbent regeneration temperature of $280 \mathrm{~K}$ via the same heat exchanger. Thermal distributions within the adsorbent bed were measured and demonstrated temperature characteristics as expected by an adsorbent bed under loading. Even $\mathrm{CO}_{2}$ loading on the adsorbent was achieved at an amount similar to that observed in previous simpler loading experiments [2]. The adsorbent was regenerated under a simulated Martian $\mathrm{CO}_{2}, 0.8 \mathrm{kPa}$ environment.

Thermal modeling predicted Demonstrator warming trends well. The actual time to warm the adsorbent was $25 \%$ longer than that predicted. It is suspected that the difference is primarily due to the absence of insulation around the Demonstrator's external heat exchanger during testing.

To best calibrate pre-existing thermal models of the adsorbent during regeneration, insulation should be added to the Demonstrator and the tests should be repeated. Specifically, once this testing is performed, the thermal models can be better calibrated with test data to capture the effect of the $\mathrm{CO}_{2}$ heat of desorption.

Further, original warming of the Demonstrator was performed with warm, dry gas due to test bed limitations. However, in the actual application, moisture in the ventilation loop should condense in the adsorbent-toventilation loop heat exchanger, first aiding the adsorbent warming. The condensate will probably at first freeze because the adsorbent bed is initially below freezing temperatures. The resulting ice layer on the ventilation loop-side of the heat exchanger may eventually impede heat transfer.

To observe this competing effect of water condensing and freezing on the fins of the adsorbent-to-ventilation loop heat exchanger, the Demonstrator could be tested using moist ventilation gas during the warming phase (desorb mode). To do this, a humidifier subsystem will need to be designed and implemented in the test bed to deliver the correct humidity levels at the ventilation loop pressure.

Finally, little work has been performed evaluating MTSA at the system level. Preliminary sizing has been performed for an adsorbent bed/heat exchanger assembly, the major component of a MTSA system [1]. Small feasibility experiments and modeling have been on-going to asses the design and performance of that assembly [2, 3]. Of a larger picture, a Martian $\mathrm{LCO}_{2}$ plant architecture was presented to communicate the process of acquiring and storing the $\mathrm{LCO}_{2}$ resource on Mars [1]. Evaluation of possible MTSA systems should begin to assess architecture decisions, operations and identify any challenges in MTSA implementation.

Thus, the objectives of this work are as follows:

1) Design and implement test bed modifications such that the Demonstrator can be tested with simulated moist, warm ventilation gas.

2) Perform additional testing with an insulated Demonstrator using both $d r y$ and moist ventilation gas to a) better calibrate adsorbent thermal models and b) observe heat transfer effectiveness of water condensation and icing on the heat exchanger fins.

3) Calibrate thermal models of the adsorbent during regeneration to simulate the effect of $\mathrm{CO}_{2}$ heat of desorption. This will be performed with Thermal Desktop $^{\circledR}$ software.

4) Evaluated the impact of MTSA on a PLSS architecture and operations by performing thermal balances assuming a specific PLSS architecture. NASA's Extravehicular Activity System Sizing Analysis Tool (EVAS_SAT), a PLSS system evaluation tool, will be used to eventually facilitate sizing analyses as the MTSA system architecture matures.

\section{DEMONSTRATOR TESTING}

DEMONSTRATOR DESCRIPTION - Details of the Demonstrator design and modeling are described elsewhere [3]. In general, the Demonstrator is a doublepipe heat exchanger. Adsorbent ( $\mathrm{NaX} 1 / 16$ " pellets, UOP) resides in the center pipe while warm ventilation loop/coolant passes at different times through the outer pipe. Longitudinal fins in both pipes serve to increase heat transfer.

The Demonstrator used several thermocouples to collect temperature data throughout the tests. These thermocouples were numbered/named in the following manner (see Figure 1 and Figure 2 for reference):
Comment: Trying to convey how we have very little opportunity to explore this concept (i.e. funding) and that we try to gain more information out of what we already have (models, the Demonstrator, the test bed...). 
- Thermocouples (TC's) 1-5 were placed in the center of the adsorbent material at 5 equally spaced axial positions, with 1 being the inlet/top of the Demonstrator and 5 being at the outlet/bottom.

- TC 6-8 were placed at the radial midpoint of the adsorbent material, between the interior fins. TC 6 , 7 and 8 are in the same plane as TC 2, 3 and 4, respectively.

- VL Inlet and VL Outlet (not shown in the figures) are the inlet and outlet temperatures of the ventilation loop gas which enter and exit through the external heat exchanger.

- The Top and Bottom Fin TC's are at the top and bottom of the Demonstrator and run through an external fin to butt up against the inner canister containing the adsorbent.

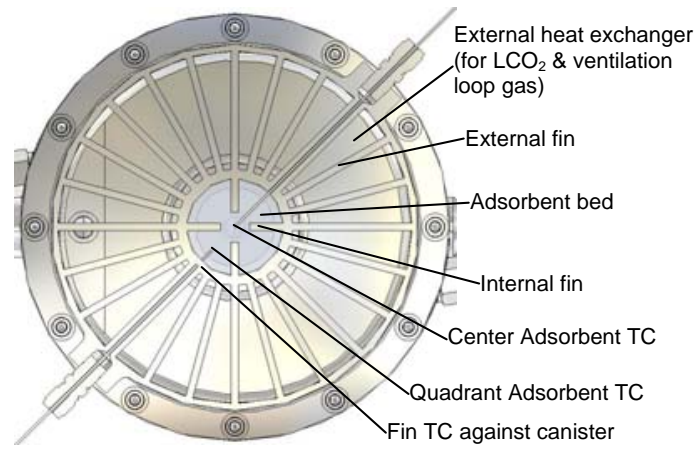

Figure 1: Axial cross section of Demonstrator

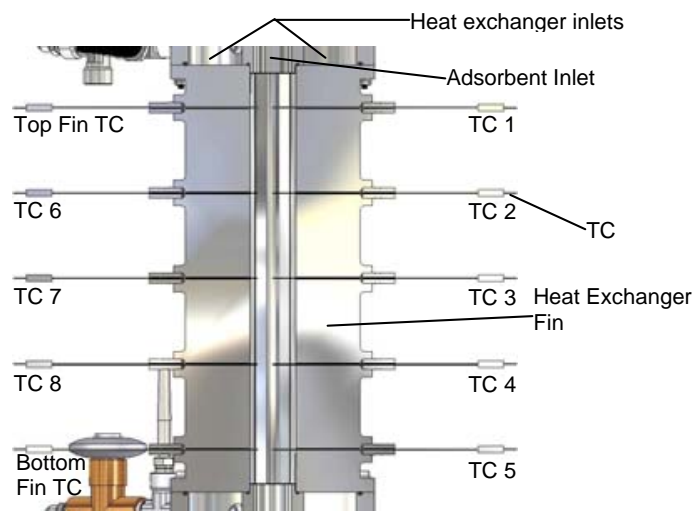

Figure 2: Longitudinal cross section of Demonstrator

TEST OBJECITVES - Initial testing of the Demonstrator was performed to characterize its general performance using dry, simulated ventilation loop gas and no outer insulation on the external heat exchanger. In general, the time to warm the Demonstrator during desorbs mode was $25 \%$ longer than predicted by the Thermal Desktop ${ }^{\text {TM }}$ models (Paragon SDC Document 060090031-801A-PI Sorbent Thermal Model). The difference is thought to be the lack of insulation (which the model assumes is present) as well as uncertainties in modeling the heat of desorption of carbon dioxide $\left(\mathrm{CO}_{2}\right)$. Thus, it would be beneficial to test the Demonstrator again with insulation. Then these data could be used to better calibrate the Thermal Desktop ${ }^{\mathrm{TM}}$ model and ensure we are correctly modeling the effect of $\mathrm{CO}_{2}$ adsorption/desorption.

Second, the external heat exchanger of the Demonstrator is designed to handle moisture in the simulated ventilation loop gas. Water will condense on the fins inside the heat exchanger as it warms from $210 \mathrm{~K}$ to $280 \mathrm{~K}$ and eventually collect in a condensate collection cup at the bottom of the heat exchanger. There will be two competing effects in this process. One, the heat of condensation could aid in warming the adsorbent. Two, freezing of that condensate would lower the convection coefficient and hinder heat transfer from the ventilation loop gas to the fins. The effect of water in the ventilation loop was not tested since the test bed did not have the capability to generate humidity at the time of testing.

Given these two issues, more testing was performed. Specifically, the following objectives were targeted:

1) The first objective will be to operate the insulated Demonstrator through a full adsorbent bed cycle with dry, simulated ventilation loop gas. The time to warm the Demonstrator will be compared with past tests without insulation and against modeling results.

2) The second objective will be to operate the insulated Demonstrator through a full adsorbent bed cycle. During adsorb mode, a dry simulated ventilation loop gas will be used (through the adsorbent bed). During desorb mode, a moist, simulated ventilation loop gas will be used (through the external heat exchanger). This is done to observe the effects of the water condensing (and possibly freezing) on the fins. Water content in and out of the external heat exchanger will be measured. The time to warm the Demonstrator will be compared with past tests without insulation and against modeling results.

TEST SET-UP - The original test bed used in Demonstrator testing was modified to include a humidifier subsystem for simulating the moisture in a ventilation loop. Figure 3 shows the test bed operated in desorb mode, with the modifications shaded. Other parts are listed for reference. A detailed description of the entire test bed and parts is provided elsewhere [3]. 


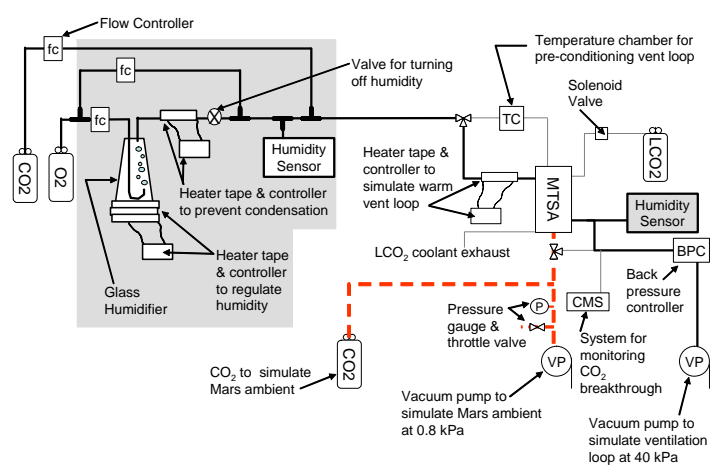

Figure 3: Test bed schematic (desorb mode) with humidifier and humidity sensors (shaded regions)

To minimize cost, the humidifier was designed in-house by Paragon and built by the University Of Arizona Department Of Chemistry Glass Shop. Heated water is contained in a glass flask which contains a glass frit through which gas can be bubbled. The system is autofilling to maintain a constant humidity level for a given water temperature. The assembly is sealed with Torr Seal ${ }^{\circledR}$ (Varian, Inc.) to handle sub ambient pressure and not contaminate the water.

Simulated humidity levels are low $(0.064$ to $0.13 \mathrm{~kg}$ $\mathrm{H}_{2} \mathrm{O} / \mathrm{hr}$ as compared to $5.1 \mathrm{~kg}-\mathrm{O}_{2} / \mathrm{hr}$ in the simulated ventilation gas). A bypass is used to limit flow through the humidifier and thus control low levels of water addition to the total flow. The humidifier temperature is controlled using heater tape to a specified humidity. A humidity sensor (Vaisala) is used downstream of the humidifier to ensure requirements are met. Before the flow downstream of the humidifier recombines with the bypass flow, an additional heater and controller are used to insure no water condenses in the lines. Once the flows recombine, the dew point is below room temperature thus no additional heater tape is needed.

Another humidity sensor downstream of the Demonstrator heat exchanger assesses the amount of water condensed (along with measurements of that collected at the bottom of the Demonstrator). The humidity sensors chosen are pressure rated so that they can measure the humidity in a $40 \mathrm{kPa}$ environment.

TEST RESULTS - Testing of the insulated Demonstrator started on $8 / 2 / 2007$. Testing intermittently continued until 8/8/2007. Six test runs were performed. Of those, three yielded data of complete cycles adequate for model calibration and data analysis.

Test 8/2/2007 was a complete cycle including Demonstrator cooling, adsorbent $\mathrm{CO}_{2}$ loading, and Demonstrator warming with dry, simulated ventilation gas to desorb the adsorbent.
During Test 8/03/2007, the simulated ventilation loop gas was not cooled prior to entering the adsorbent which resulted in a warm loading cycle. The Demonstrator was taken through a full desorb cycle after the warm loading, again with dry gases.

Test 8/06/2007 was the first test to use the humidifier. During the initial start of the moist warming cycle, the humidifier pressurized and forced water, and eventually, gas up through the humidifier reservoir. Testing was terminated and the Demonstrator was again warmed using dry gases. After this test, the humidifier was modified to replace the one-way check valve with an over-pressure release valve and procedures were changed to isolate the reservoir from the humidifier with the reservoir isolation valve during operation.

Tests 8/7/2007 and 8/8/2007 were complete cycles using simulated moist ventilation gas during the warming phase.

Immediately following the moist testing on 8/8/2007, a dry test was initialized. This test terminated when the over-pressure relief valve was tripped and gases leaked through a lower o-ring seal during desorb.

After the aborted testing on $8 / 8 / 2007$, the Demonstrator was allowed to warm to room temperature and subsequently purged with nitrogen gas per the test termination procedures. The Demonstrator adsorbent showed increasing signs of contamination during testing and should be baked prior to future testing or use. Also the o-ring seals at the bottom of the Demonstrator show signs of leakage during the Demonstrator over pressurization and should be replaced. All other hardware appears to be function properly and in good working order.

Data from test 8/2/2007 (where dry gas was used during the warming cycle) were used to compare to previous testing, as the primary change in test design was the addition of insulation to the Demonstrator. This test also acted as a baseline for evaluating the impact of moisture on the warming cycle.

Data from tests 8/7/2007 and 8/8/2007 (where moist gas was used during the warming cycle) were used to evaluate the effect of adding moisture to the simulated ventilation gas. The set-up for these tests were identical to test $8 / 2 / 2007$ except that moisture was added to the simulated ventilation gas during the warming cycle.

For the most part, trends observed during testing were very similar to trends observed during previous testing (without insulation and using dry ventilation gas) [3]. The following is a summary with differences described in detail.

Adsorbent Cooling Using $\mathrm{LCO}_{2}$ - The addition of insulation on the Demonstrator reduced both the average temperature of the adsorbent after cooling and the range of temperature within the adsorbent. For
Comment: This picture will have to probably cross two columns. 
example, Figure 4 shows that the first complete test on $8 / 2 / 2007$ had average overall adsorbent temperature of $211.5 \mathrm{~K}$ with a range of $4.5 \mathrm{~K}$ across all thermocouples. This compares to an average temperature of $216 \mathrm{~K}$ with a range of $10 \mathrm{~K}$ measured during un-insulated testing.

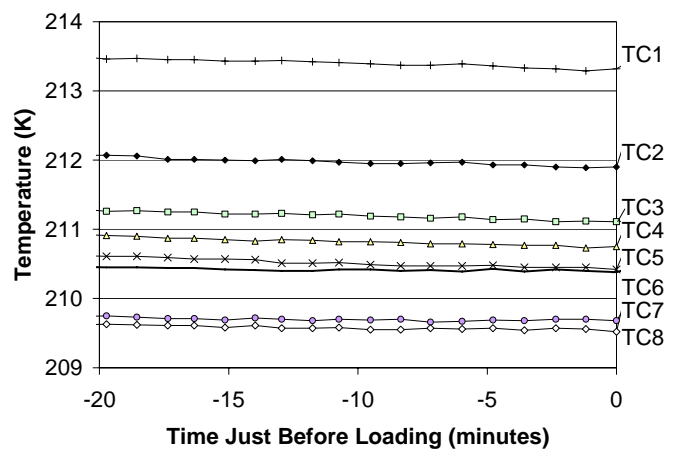

Figure 4: Adsorbent temperature data during cooling

Adsorbent Loading - General loading trends matched those observed during previous testing. For example, ventilation gas temperature at the inlet to the adsorbent bed was similar, ranging from $258-273 \mathrm{~K}$ depending upon how the test bed was operated. Also, as the adsorbent had been cooled to $\sim 212 \mathrm{~K}$ prior to loading, the adsorbent temperatures initially increased because of the relatively high temperature of the ventilation loop entering the adsorbent bed.

The effect of $\mathrm{CO}_{2}$ loading on the adsorbent temperature was also similar to previous testing [3]. As the ventilation gas flows over the adsorbent, energy is released as $\mathrm{CO}_{2}$ is adsorbed. The " $\mathrm{CO}_{2}$ front" moves down the bed as the adsorbent is filled to capacity for the given loading conditions. The location of the front as a function of time can be correlated to the temperature rise of the adsorbent (see Figure 5 for example). These characteristic temperature peaks were observed during all tests.

Further, TC 6, 7, and 8 experienced temperature peaks at nearly the same time as the center thermocouples in the same plane, indicating that the $\mathrm{CO}_{2}$ front progressed evenly through the adsorbent.

It was noted that the magnitude of the temperature peaks decreased from test to test. An example comparing TC 1 and 2 from tests 8/2/2007 and 8/7/2007 is shown in Figure 5. This indicates a lower level of $\mathrm{CO}_{2}$ loading with each subsequent test. The reduced $\mathrm{CO}_{2}$ load on the adsorbent adds a variable to the comparison of dry and moist operations as less heat will be consumed by the release of $\mathrm{CO}_{2}$ during the warming cycle.

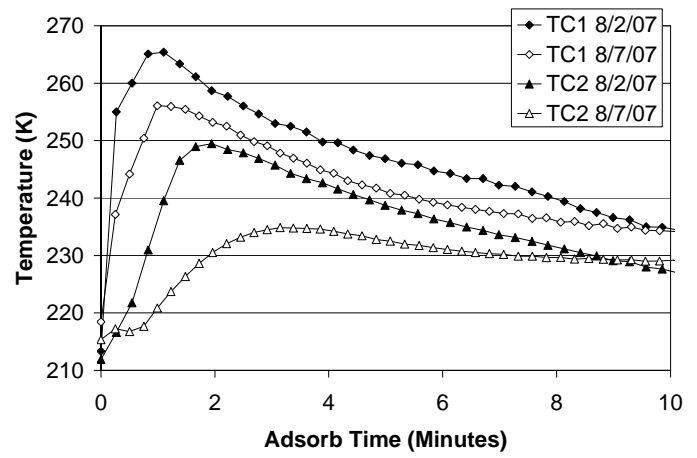

Figure 5: Center adsorbent temperatures increase as $\mathrm{CO}_{2}$ front moves along bed, but decrease from test to test

\section{Adsorbent Warming Using Simulated Ventilation Gas}

Dry Testing - During dry testing on $8 / 2 / 2007$, the average ventilation loop gas temperature at the external heat exchanger inlet was $313 \mathrm{~K}$. This temperature was reached after 6.5 minutes of operation and was 3 degrees warmer than the average ventilation gas inlet temperature measured during earlier testing.

Further analysis shows an off-nominal temperature spike in the test data that occurs during the initiation of the desorb phase. This is thought to be a result of an o-ring leak due to low temperatures that reseals as the o-rings warm. This would explain the source and growth of adsorbent contamination from test to test as $\mathrm{CO}_{2}$ and water in the moist ventilation gas would contaminate the adsorbent during this o-ring breach. Removal of water contamination would require greater temperatures and/or pressure swing than performed during the MTSA cycle and thus some contamination would remain for the later tests.

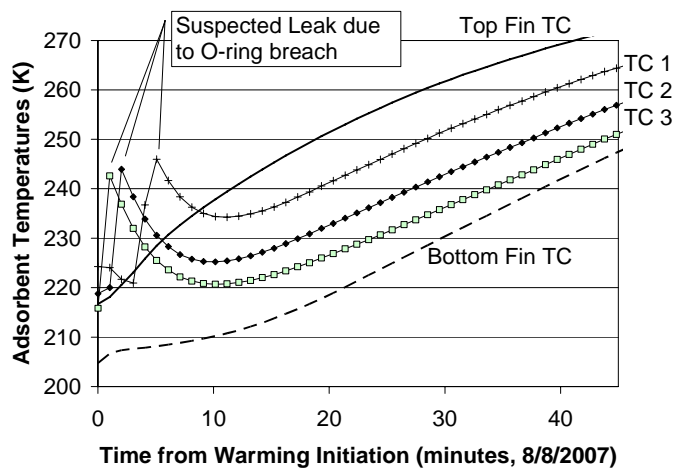

Figure 6: Adsorbent temperatures indicate spikes indicative of an o-ring breach 
The total warming time during testing on $8 / 2 / 2007$ was 94.65 minutes. This is 5 to 10 minutes faster than testing completed on the un-insulated Demonstrator. Unfortunately the test is not a truly realistic comparison as the starting temperature on the adsorbent was $5 \mathrm{~K}$ lower than earlier testing and the ventilation gas inlet temperature was $3 \mathrm{~K}$ warmer.

Also, the variation in $\mathrm{CO}_{2}$ loading plays a non-trivial role. Given the non uniform factors, a quantitative impact has not been calculated. However, this result does indicate that the addition of insulation does not drastically affect the warming time of the Demonstrator. It also indicates that the ventilation gas temperature at the heat exchanger inlet remains the dominant variable.

Moist Testing - During moist testing on 8/7/2007 and $8 / 8 / 2007$, the average ventilation gas inlet temperatures were $317 \mathrm{~K}$ and $318 \mathrm{~K}$, respectively. These temperatures are higher than any of the previous dry tests. In neither case did the inlet temperature stabilize at the average temperature but rather changed continuously throughout the warming process. This elevated temperature was likely caused by the post humidifier heat rope which was set to $358 \mathrm{~K}$. This elevated temperature was intended to prevent condensation in the transfer lines during humid operations but also appears to have raised the inlet gas temperature above the set point of the inlet heat rope that was intended to control the temperature at the heat exchanger inlet.

On $8 / 7 / 2007$ and $8 / 8 / 2007$, the total warming time was 89.9 and 84.6 minutes, respectively. While both of these times are shorter than that recorded during dry operations (up to 10 minutes), the variation in inlet temperature and $\mathrm{CO}_{2}$ loading precludes a direct comparison. Again, a qualitative assessment indicates that the addition of moisture to the simulated ventilation gas during the warming cycle does not significantly change the warming time.

Though there are many possible sources of variation in Demonstrator warming time, the average ventilation gas inlet temperature appears to be the dominant factor. A linear regression of warming time versus average ventilation gas inlet temperature shows it is possible to attribute nearly $90 \%$ of the variation in warming time to changes in ventilation gas inlet temperature, as shown in Figure 7 . This indicates that neither the addition of insulation to the Demonstrator exterior nor moisture to the ventilation gas during warming significantly affect the warming time of the Demonstrator.

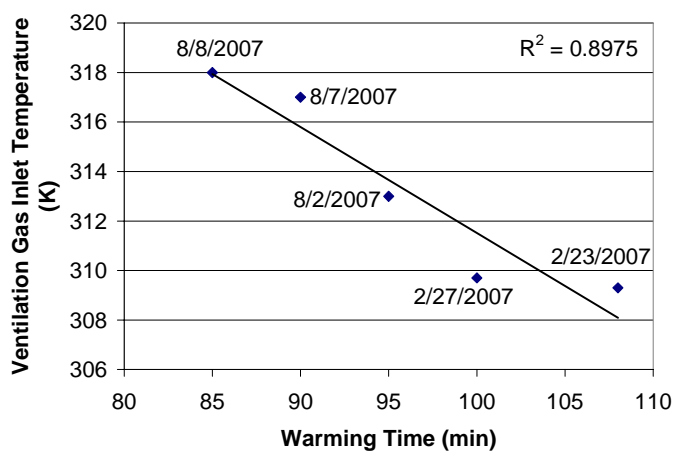

Figure 7: Warming time verses average ventilation gas inlet temperature for multiple tests

While the thermal response of the system is not drastically changed by the addition of moisture, it does complicate the operation of the system. During testing on $8 / 7 / 2007,107.9 \mathrm{~g}$ of water was condensed out of the ventilation gas. During testing on $8 / 8 / 2007,135.9 \mathrm{~g}$ of water was condensed out of the ventilation. On both occasions less than $50 \mathrm{~g}$ of water was collected during condensate purge. This indicates that there was ice buildup in the external heat exchanger that did not melt during the warming period prior to the condensate purge.

Figure 8 shows example data from the 8/7/2007 test. Corresponding Demonstrator temperatures are shown in Figure 9. Almost all of the water is condensed out of the ventilation gas during the first 45 minutes of warming, before the upper portion of the adsorbent casing reaches $279 \mathrm{~K}$. As the adsorbent and casing (or "fin") temperatures continue to rise, less water is condensed.

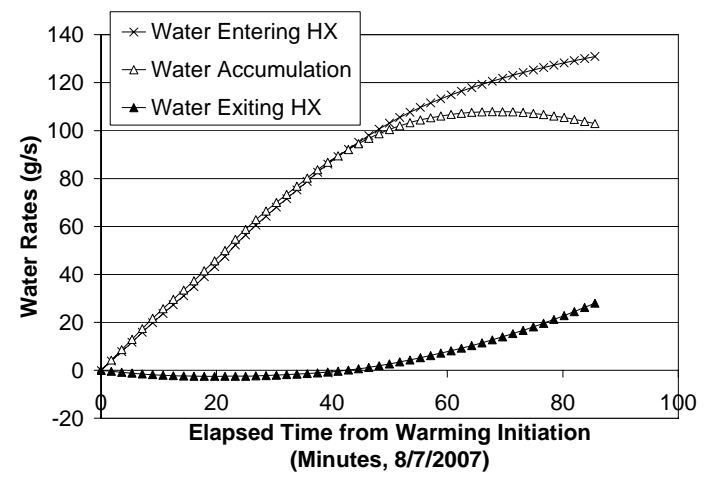

Figure 8: Example water accumulation in heat exchanger 


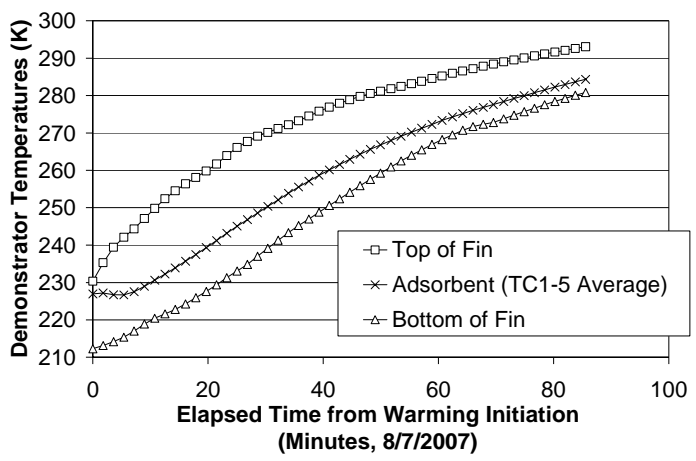

Figure 9: Example Demonstrator temperatures during desorb mode

From 60 to 70 minutes, little water is being condensed. This occurs once the average adsorbent temperature reaches approximately $273 \mathrm{~K}$. The top fin temperature is $285 \mathrm{~K}$. It is assumed that during this period, any ice present is melting.

Approximately 70 minutes into the warming, the accumulation decreases indicating that more water is exiting the demonstrator than entering. This occurs as the coldest temperature, the bottom of the adsorbent casing or "bottom fin" temperature, achieves $274 \mathrm{~K}$. The upper casing is 9 degrees $\mathrm{K}$ above the target adsorbent temperature of $280 \mathrm{~K}$. At these conditions, the heat exchanger is too warm to condense the moisture and instead, humidifies it further with water now melted.

\section{ADSORBENT MODEL CALIBRATION}

MODEL DESCRIPTION - A model created with Thermal Desktop $^{\text {TM }}$ software of the Demonstrator in desorb mode was modified from the original [3] to match the as-built Demonstrator parameters.

The model consists of a 45 degree symmetric wedge of the Demonstrator unit, from the center of the adsorbent, out to, and including the inner canister that contains the adsorbent. The external heat exchanger of the Demonstrator was modeled using fluid paths and connected to the inner canister material using contactors with a heat transfer coefficient determined from previous work [3]. Actual dimensions include the following:

- Height: 12 inches

- Canister inner diameter: 1.34 inches

- Canister outer diameter: 1.6 inches

- Number of adsorbent fins: 4

- Adsorbent fin thickness: 0.1 inches

- Adsorbent fin length: 0.47 inches $(70 \%$ of Adsorbent Radius)

- Canister temperatures: based on test data

- Initial adsorbent temperatures: Based on test data
- Canister and fin material: 304 Stainless Steel

- Flow rate through external heat exchanger: $5.11 \mathrm{~kg} / \mathrm{hr}$

- Ventilation gas pressure: $40 \mathrm{kPa}$

- Ventilation gas: oxygen

- Ventilation gas temperature: based on test data for each run

MODEL VERIFICATION - The model was verified by matching the model calculated heat input (Q) from a boundary node to a hand calculation of $\mathrm{Q}=\mathrm{m}^{*} \mathrm{Cp} \mathrm{p}^{\star} \mathrm{dT}$ over a prescribed period of time where $m$ is the mass in $\mathrm{kg}$ (of the adsorbent, canister, and fin), $\mathrm{Cp}$ is the specific heat in $\mathrm{kJ} / \mathrm{kg}-\mathrm{K}$ (of the adsorbent and 304 stainless steel) and dT is the temperature difference in Kelvin.

It was discovered that, for cylinder walls modeled as one node thick, Thermal Desktop ${ }^{\circledR}$ software calculates the volume of the inner cylinder based on a thin plane equation (thickness*height*arc length) rather then using a hollow cylinder equation. This method is good for thin cylinders, but not for thicker cylinders. Therefore, to correctly model the volume, and hence total mass of material in the Demonstrator adsorbent canister, the thickness was modified to correctly represent the material being heated in the Demonstrator. Once the volume of the canister material was the same in both the model and the hand calculation, the $\mathrm{Q}$ value of a surface heat load in the model matched the $\mathrm{Q}$ value of the hand calculations over a given temperature and time difference. This verification demonstrated appropriate heat transfer throughout the solid portions of the model as well as verifying the material properties were correctly applied in the model.

CASE DESCRIPTION - Data from test 8/2/2007 (using dry simulated ventilation gas) was used in initial analyses. Due to the adsorbent temperature spikes observed in the intial period of the warming phase, all modeling was intiatied after this spike, at the lowest temperatures. In the case of the data run on $8 / 2 / 2007$, this was 650 seconds (and is exemplified in Figure 10).

Data from each thermocouple are compared against data from the model nodes that represent the same locations in the model. These comparisons will be used to model performance.

As most of the parameters in the Demonstrator are set, such as the physical dimensions, or are very well known, such as the 304 SS properties, the variables available to modify to get the adsorbent regeneration model to more closely align with the test data include the $\mathrm{Cp}$ and thermal conductivity $(k)$ of the adsorbent, as well as the heat transfer coefficient $(h)$ of the ventilation gas in the external heat exchanger.

INITIAL MODEL RESULTS \& MODIFICATIONS - Once the model was updated to represent the actual Demonstrator, the model was run. The results were plotted along with test data collected on 8/2/2007. 
Results show that both the canister temperatures and adsorbent temperatures increase much faster in the model than measured during the test. Since the model temperatures were increasing much faster than the test data, it was assumed that the effective heat transfer coefficient of the ventilation loop gas in the external heat exchanger was modeled too high.

Model data further indicated warmer outlet ventilation gas temperatures than measured during the test. Thus, more heat was being pulled out of the ventilation gas in the test then in the model. To more accurately model the outlet temperature of the ventilation gas, the mass of the external heat exchanger needed to be modeled in addition to the internal canister. To do this, the internal canister thickness was increased to account for the total stainless steal mass in a 45 degree wedge of the Demonstrator. The canister was still modeled as a single node thickness so the thermal gradient across a thicker material was not a concern.

The results show the top of the canister and adsorbent temperatures match between the model and the test data. However, temperatures of the bottom of the canister and adsorbent are significantly lower in the model compared to the test data, as well as the ventilation gas temperatures. From this information it was determined that the heat exchanger material was probably not all at the same temperature, and, therefore, could not be simply modeled as an increased thickness to the inner canister.

Since modeling the ventilation loop was not necessary to correctly model the adsorbent, the ventilation loop portion of the model was removed. Not only does this remove the uncertainty of accurately modeling the various Demonstrator material temperatures but it also removes the uncertainty of correctly modeling the heat transfer coefficient of the vent loop, leaving only $\mathrm{Cp}$ and $\mathrm{k}$ of the adsorbent as unknowns.

Instead, 5 boundary nodes were created and attached to the canister material. The 5 boundary nodes corresponded with the 5 axial nodes in the model as well as with the 5 axial thermocouples incorporated in the Demonstrator. Incorporated into the new boundary nodes was an array of temperatures versus time data gathered throughout the test to simulate the internal canister temperatures. Since test data was only available for the top and bottom nodes, the data was linearly interpolated to determine the temperatures of the middle nodes. As the model was run, the canister temperatures in the model match exactly the test data, showing that the canister temperatures had been accurately incorporated into the model.

MODEL CALIBRATION - Initial results indicate that the $\mathrm{Cp}$ of the adsorbent was modeled too high, as the model adsorbent temperatures at the bottom of the Demonstrator were significantly lower then the test data.
Initially the adsorbent was modeled as having a $\mathrm{Cp}$ of $3225 \mathrm{~J} / \mathrm{kg}-\mathrm{K}$, which accounted for the actual adsorbent Cp of $900 \mathrm{~J} / \mathrm{kg}-\mathrm{K}$ plus an effective Cp of $2325 \mathrm{~J} / \mathrm{kg}-\mathrm{K}$ due to the heat of desorption of the $\mathrm{CO}_{2}$ [3]. Neglecting the effective $\mathrm{Cp}$ provided far better results, which are shown in Figure 10 and Figure 11.

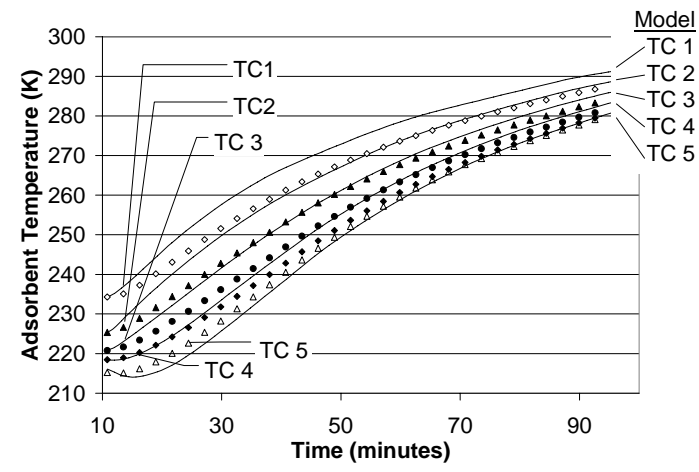

Figure 10: Model results of adsorbent center temperatures versus $8 / 2 / 2007$ test data

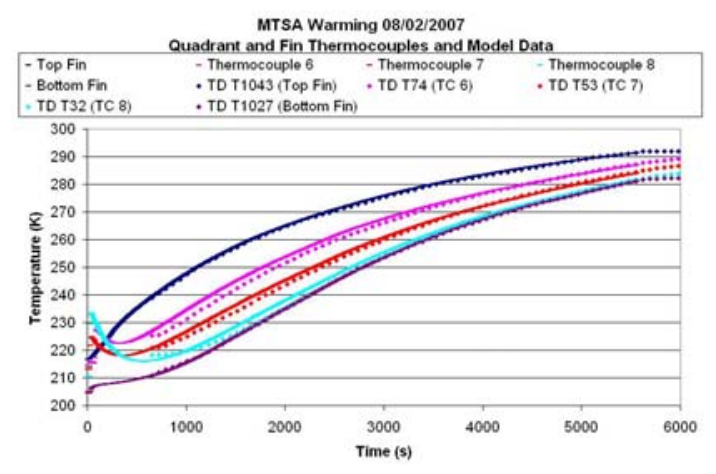

Figure 11: Model results of fin and adsorbent quadrant temperatures versus 8/2/2007 test data

The model match the test data very well towards the outlet, at the center near TC 5 , while the model shows slightly higher temperatures for the other center thermocouples (TCs 1-4). The model matches very closely with temperatures measured in the quadrant areas, TC's 6-8.

The model was run assuming initial conditions as experienced during 2/23/2007 without insulation and maximum loading [3], and 8/8/2007 with insulation and minimal loading. The model performance as compared to the test data is similar for both cases as that seen in Figure 10 and Figure 11.

One reason for the difference in TC's 1-4 may be inherent in the model setup, as there are only 5 radial nodes in the adsorbent. The model nodes on the fin
Comment: We might want to include a paragraph addressing why the original assessment did not work (i.e. the $\mathrm{cp}$ was applied to the entire mass the $\mathrm{cp}$ was applied to the entire mas
of the adsorbent when it maybe should have only been applied to the mass of the adsorbed $\mathrm{CO} 2$ ).
Comment: Figures will be formatted for better clarity... (see figure above for example) 
only line up with the nodes on the adsorbent at either 50 or $75 \%$ fin length when compared to the radius of the adsorbent. When the fin is modeled as built, or at $-70 \%$, then the fin takes the information from the nearest adsorbent node, which is at $75 \%$, so the model is actually modeling a $75 \%$ fin length rather then a $70 \%$. This would show a faster temperature increase in the model then the test since there is a greater fin length conducting heat into the adsorbent, which is seen in Figure 10 and Figure 11.

\section{MTSA PLSS SYSTEM THERMAL MODELING}

MISSION \& ENVIRONMENT ASSUMPTIONS - The mission under consideration is Extravehicular Activity (EVA) performed on the surface of Mars. It is assumed that an EVA is 8 hours in duration. Several requirements are imposed on a Portable Life Support System (PLSS) for use during an EVA.

The ventilation loop operating pressure is assumed to be $29.65 \mathrm{kPa}$ (4.3 psi).

The volumetric flow rate requirement at the helmet is 0.11 actual cubic meter pre minute (ACMM), or 4.0 actual cubic feet per minute (ACFM), assuming a suit pressure of $30 \mathrm{kPa}(4.3 \mathrm{psi})$ and an inlet gas temperature of $15.6^{\circ} \mathrm{C}\left(60^{\circ} \mathrm{F}\right)$. This flow rate provides visor de-fogging, carbon dioxide and humidity washout of the oral-nasal area, and head/face cooling, assuming a hemispherical helmet design.

The conditions in the helmet are fairly constant $(30 \mathrm{kPa}$ and approximately $15.6^{\circ}$ to $29.4^{\circ} \mathrm{C}$ ). However, when the 0.11 ACMM flows through the PLSS, temperatures of the ventilation gas change (especially in the MTSA subsystem). Thus, this is used to calculate the mass flow requirement which will remain constant throughout the ventilation loop [approximately - changes due to water and carbon dioxide $\left(\mathrm{CO}_{2}\right)$ removal that is then replenished with pure oxygen $\left(\mathrm{O}_{2}\right)$ cause small changes at various points in the ventilation loop].

The average metabolic rate per crewmember is $300 \mathrm{~W}$. The lowest metabolic rate assumed is two intervals of $100 \mathrm{~W}$ for 50 continuous minutes each.

$\mathrm{O}_{2}$ consumption and $\mathrm{CO}_{2}$ generation is assumed to vary linearly with respect to metabolic rate. Respiratory quotient, the molar ratio of $\mathrm{CO}_{2}$ produced to $\mathrm{O}_{2}$ consumed, is assumed to be 0.90 . For example, $25 \mathrm{mg}$ $\mathrm{CO}_{2} / \mathrm{s}$ is produced at $300 \mathrm{~W}$ metabolic rate.

The total water flow rate through the suit is composed of that delivered to the helmet for user comfort plus that generated by the user. This water flow rate is captured in Figure 12 as a function of metabolic rate.

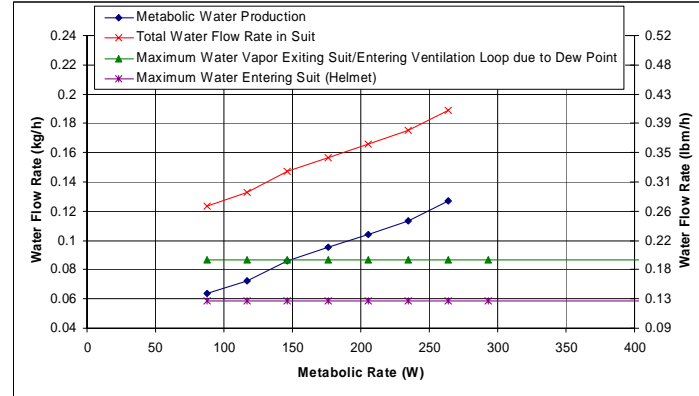

Figure 12: Water supply to the ventilation loop as a function of metabolic rate ${ }^{1}$

For this study, it is assumed that at 0.11 ACMM (4 ACFM), the PLSS is to receive water at a dew point as high as $288.7 \mathrm{~K}\left(60^{\circ} \mathrm{F}\right)$ and deliver it back to the helmet at no higher than $283.1 \mathrm{~K}\left(50^{\circ} \mathrm{F}\right)$ dew point. This corresponds to removing a minimum of $0.025 \mathrm{~kg} / \mathrm{h}(0.06$ $\mathrm{lb}_{\mathrm{m}} / \mathrm{h}$ ) of water. Controlling the dew point to less than $283.1 \mathrm{~K}$ at the inlet to the suit is the ultimate driver. (It is thought that the allowable dew point range is from $272 \mathrm{~K}$ $\left(30^{\circ} \mathrm{F}\right)$ to $\left.283.1 \mathrm{~K}\left(50^{\circ} \mathrm{F}\right)\right)$.

Thus, it is assumed that the water vapor exiting the suit and entering the ventilation loop of the PLSS is limited due to condensation in the suit. It is limited by the liquid cooling and ventilation garment (LCVG) temperature which drives a maximum dew point temperature of $\sim 15^{\circ} \mathrm{C}\left(60^{\circ} \mathrm{F}\right)$ exiting the suit. This is assumed because the gas in the suit flows over the LCVG before entering the ventilation loop of the PLSS.

Assuming a $\sim 15^{\circ} \mathrm{C}\left(60^{\circ} \mathrm{F}\right)$ dew point at 0.11 ACMM (4 ACFM), the max water vapor flow rate leaving the suit is capped at $0.08 \mathrm{~kg} / \mathrm{h}(0.19 \mathrm{lb} / \mathrm{h})$. Any total water flow rate in the suit above this will condense in the suit due to the dew point. This study assumes the maximum water flow rate and thus is constant regardless of metabolic rate, as shown in Figure 12.

The ventilation gas temperature entering the helmet is assumed to be between $277.1 \mathrm{~K}\left(39^{\circ} \mathrm{F}\right)$ to $305.1 \mathrm{~K}$ $\left(90^{\circ} \mathrm{F}\right)$. This requirement specifies the upper and lower bounds for the thermal control system to maintain crew comfort across all metabolic profiles for EVA.

Three Mars operating environments are assumed to evaluate the MTSA PLSS schematic. - Table 1 defines the conditions for "hot," "nominal," and "cold" Martian environments. These are intended to represent the range of conditions that can be experienced on Mars during an EVA. To explore the coldest environment anticipated, it is also assumed that the astronaut

${ }^{1}$ Assuming $0.11 \mathrm{ACMM}$ ventilation loop flow rate, $15^{\circ} \mathrm{C}$ dew point at exit of LCVG
Comment: Figure will be reformatted for clarity.

Comment: This seems wordy. Would like to reduce this to only two paragraphs.

Comment: Need to check this number 
performs at a metabolic rate of $100 \mathrm{~W}$ for 100 minutes while in the Mars cold environment.

\section{Table 1: Assumed Martian environments}

\begin{tabular}{|l|r|r|r|}
\hline Mars Cases & Hot & Nominal & Cold \\
\hline Incident Solar, Btu/h- $-\mathrm{ft}^{2}$ & 55 & 35 & 19 \\
\hline Surface Temperature, ${ }^{\circ} \mathrm{F}$ & 80 & -78 & -167 \\
\hline $\begin{array}{l}\text { Atmosphere Temperature, } \\
{ }^{\circ} \mathrm{F}\end{array}$ & 80 & -78 & -167 \\
\hline $\begin{array}{l}\text { Atmosphere Pressure, } \\
\text { psia }\end{array}$ & 0.145 & 0.124 & 0.087 \\
\hline Sky Temperature, ${ }^{\circ} \mathrm{F}$ & -208 & -208 & -208 \\
\hline Wind Speed, ft/sec & 66 & 33 & 16 \\
\hline $\begin{array}{l}\text { Suit View Factor to } \\
\text { Ground }\end{array}$ & 0.5 & 0.5 & 0.5 \\
\hline
\end{tabular}

The heat leakage to the environment is calculated for each environment by an algorithm within EVAS_SAT. The resulting total (suit + PLSS + Display and Control Module) heat leakages for the three Martian environments are: hot $30.4 \mathrm{~W}$, nominal $113.6 \mathrm{~W}$, and cold $153.2 \mathrm{~W}$.

MODEL CONSTRUCTION \& ASSUMPTIONS - NASA'S Extravehicular Activity System Sizing Analysis Tool (EVAS_SAT) is being used to perform overall PLSS modeling [4]. EVAS_SAT is an Excel workbook that predicts power, mass, and volume for EVA systems based on internal and user-defined sizing algorithms. The EVAS_SAT sizing algorithms are based on several parameters including EVA duration, metabolic rate, suit pressure, and operating environment.

To include MTSA technology in EVAS_SAT, a MTSA user-defined algorithm was developed in Excel and installed.

MTSA PLSS Architecture - There are various ways to apply MTSA to a PLSS. As the technology is new, the architecture is far from optimized. But to facilitate the analysis, an architecture had to be assumed.

A functional schematic of the PLSS architecture used in developing the MTSA system thermal model is shown in Figure 13. The ventilation loop gas exits the LCVG at temperature $T_{1}$, humidity ratio $w_{1}$, and mass flow rate $\mathrm{m}_{\mathrm{O} 2}$. The mass of the carbon dioxide is neglected. The ventilation loop gas is heated to $T_{2}$ by an air bearing fan.

The moist, warmed ventilation loop gas warms an adsorbent bed via a condensing ice heat exchanger (labeled 1) and desorbs the metabolically-produced $\mathrm{CO}_{2}$ previously collected. Heat required to desorb the metabolically-produced $\mathrm{CO}_{2}$ is transferred both from the ventilation gas particles and via water condensing out of the ventilation loop gas stream. At the end of the warming cycle, the ice melts. The water is gravity fed to the feedwater accumulator through a check valve at mass flow rate $m_{\text {cond. }}$ Through this condensing ice heat exchanger (1), the ventilation loop gas temperature is lowered to $\mathrm{T}_{3}$.

Water is further removed in a silica gel bed at rate $m_{a b s}$. The heat of water adsorption raises the gas temperature to $T_{4}$. The gas is cooled to $T_{5}$ via a recuperative heat exchanger (labeled 2) with another portion of the ventilation loop.

The bed in adsorb mode is modeled as a two-stage heat exchanger: the first heat exchanger (labeled 4) models the $\mathrm{CO}_{2}$ coolant phase change from liquid to vapor, followed by the second heat exchanger (labeled 3), which superheats the $\mathrm{CO}_{2}$ vapor. Thus, the ventilation loop gas is cooled from $T_{5}$ to $T_{7}$. The heat of $\mathrm{CO}_{2}$ adsorption is removed by the $\mathrm{LCO}_{2}$ coolant.

The ventilation loop gas, now free of metabolicallyproduced $\mathrm{CO}_{2}$, is warmed through the recuperative heat exchanger (2) to $T_{8}$. It is further warmed to $T_{9}$ and humidified to $w_{9}$ at a water addition rate of $m_{\mathrm{H} 2 \mathrm{O}}$ in the heat exchanger and humidifier (labeled 5). After oxygen is replenished by the oxygen subsystem, the final temperature and humidity ratio entering the LCVG are $\mathrm{T}_{10}$ and $\mathrm{w}_{10}$, respectively.

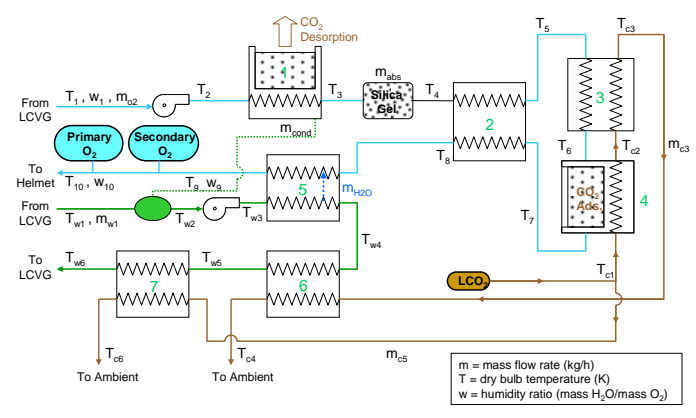

Figure 13: MTSA functional schematic

The pressurized $\mathrm{LCO}_{2}$ is delivered at temperature $T_{C 1}$ to both the adsorbing bed and $\mathrm{LCO}_{2}$-to-liquid heat exchanger (7). At the bed, the $\mathrm{LCO}_{2}$ is expanded to a solid and sublimated in heat exchanger 4 to a temperature $T_{c 2}$ (the same as $T_{c 1}$ ) and mass flow rate of $\mathrm{m}_{\mathrm{c} 3}$. The now gaseous $\mathrm{LCO}_{2}$ is warmed to $T_{\mathrm{c} 3}$ in heat exchanger 3. The gaseous $\mathrm{LCO}_{2}$ exhaust is fed to the $\mathrm{LCO}_{2}$-to-liquid heat exchanger which is modeled as two heat exchangers (labeled 6 and 7 ) and exhausts at temperature $\mathrm{T}_{\mathrm{c} 4}$. The extra $\mathrm{LCO}_{2}$ used for specifically cooling the user is cooled to $T_{c 6}$.

Additional Modeling Assumptions - Assumptions in modeling the MTSA subsystem are listed in Table 2 and include:

- Moist gas mixtures are treated as ideal gas mixtures. 
- Temperature variations in specific heats are assumed negligible for the temperature ranges considered in the analysis.

- The ideal gas approximation is used for all gasses, including saturated vapor.

- Quantities known only at 117.2 W (400 Btu/h) and 468.9 W (1600 Btu/h) metabolic rates are linearly interpolated to other metabolic rates, as needed.

- Transient effects are not considered. Average conditions are used throughout the analysis.

- All MTSA system components are adiabatic with respect to the surrounding environment.

- The effectiveness of heat exchangers $2,3,6$, and 7 are assumed equal to 0.9 .

- Water pump power $=33.25 \mathrm{~W}$

- $\quad \mathrm{LCO}_{2}$ tank storage pressure $=5612 \mathrm{kPa}(814 \mathrm{psia})$

- Adsorbent bed specific heat $=0.9 \mathrm{~kJ} / \mathrm{kg}-\mathrm{K}$

- $\mathrm{CO}_{2}$ adsorbent/desorbent heat exchanger specific heat $=0.9 \mathrm{~kJ} / \mathrm{kg}-\mathrm{K}$

- Silica gel heat of adsorption $=3024 \mathrm{~kJ} / \mathrm{kg}$ of adsorbed $\mathrm{H}_{2} \mathrm{O}\left(1300 \mathrm{Btu} / \mathrm{l} \mathrm{b}_{\mathrm{m}}\right)$

- Constant MTSA half-cycle $=5 \mathrm{~min}$

- All metabolic $\mathrm{CO}_{2}$ is removed from the ventilation gas in a half-cycle

Table 2: Assumed gas and water conditions

\begin{tabular}{|l|l|c|c|}
\hline & Metabolic Rate (W) & 117 & 469 \\
\hline $\begin{array}{l}\text { Gas entering } \\
\text { ventilation } \\
\text { loop }\end{array}$ & $\mathrm{T}_{1}(\mathrm{~K})$ & 299.8 & 297.0 \\
\cline { 2 - 4 } & Dew Point (K) & 288.7 & 288.7 \\
\hline $\begin{array}{l}\text { Gas exiting } \\
\text { ventilation } \\
\text { loop }\end{array}$ & $\mathrm{T}_{10}(\mathrm{~K})$ & 288.7 & 291.5 \\
\cline { 2 - 4 } & Dew Point (K) & 283.1 & 283.1 \\
\hline $\begin{array}{l}\text { Water entering } \\
\text { LCVG }\end{array}$ & $\mathrm{m}_{\mathrm{w} 1}(\mathrm{~kg} / \mathrm{hr})$ & 91 & 91 \\
\cline { 2 - 4 } & $\mathrm{Tw6}$ & 302.6 & 288.7 \\
\hline
\end{tabular}

The cooling load estimates generated by EVAS_SAT are used by the MTSA thermal analysis through the calculation of the cooling water leaving the LCG. The enthalpy of the water leaving the LCG is calculated by adding the water loop cooling load to the known LCG inlet enthalpy. The water loop load is the total suit load, as calculated by EVAS SAT, minus the ventilation loop load, minus the net MTSA cooling, and minus the water pump power. (The heat generation associated with the water pump is part of the total cooling load calculated by EVAS SAT. Since this component is incorporated in the MTSA system modeling, its contribution to the EVAS SAT load estimate is subtracted to prevent double counting.) The corresponding water temperature is calculated using the specific heat of water.

Model verification - Two tools were built, independently of each other, for performing MTSA system performance calculations as represented in Figure 13. Results of those models were compared. Differences were identified and explained. Model corrections were performed and/or a consensus on how to model a given phenomenon was achieved. In the end, all authors agreed to the methods used and the results attained.
SYSTEM MODELING RESULTS - Results indicate the environment has little effect on the $\mathrm{CO}_{2}$ removal and humidity subsystems. In other words, the ventilation loop and the MTSA subsystem are not affected. Gas temperatures, mass flow rates and humidity ratios are the same for all three cases. This is primarily a result of the fixed PLSS inlet and outlet conditions in the ventilation loop and the assumption that the MTSA components are all adiabatic with respect to their surroundings.

The effect of the increase in environment temperature is captured in the water loop modeling. As more cooling is required by the user, the water temperature entering the PLSS (Tw1) is warmer for warmer environments. This temperature drives the cooling required by the $\mathrm{LCO}_{2}$-toliquid heat exchanger (labeled 6 and 7). Thus, for warmer environments, more $\mathrm{LCO}_{2}$ coolant is required for cooling. This is reflected by an increase in the $\mathrm{LCO}_{2}$ mass flow rate $m_{c 5}$ to maintain the LCVG water return temperature (Tw6) at $295.4 \mathrm{~K}$.

Example results are shown in Figure 14 for a Mars nominal environment. The $\mathrm{LCO}_{2}$ flow rate to heat exchanger $7\left(\mathrm{~m}_{\mathrm{c} 5}\right)$ increased to $1.29 \mathrm{~kg} / \mathrm{hr}$ for the Mars hot environment and decreased to $0.61 \mathrm{~kg} / \mathrm{hr}$ for the Mars cold environment. It should be noted that T6 is a couple degrees less than T7, a modeling artifact from representing the MTSA bed as two heat exchangers. This is not a significant issue but it will remain on a list of items to be investigated in the future.

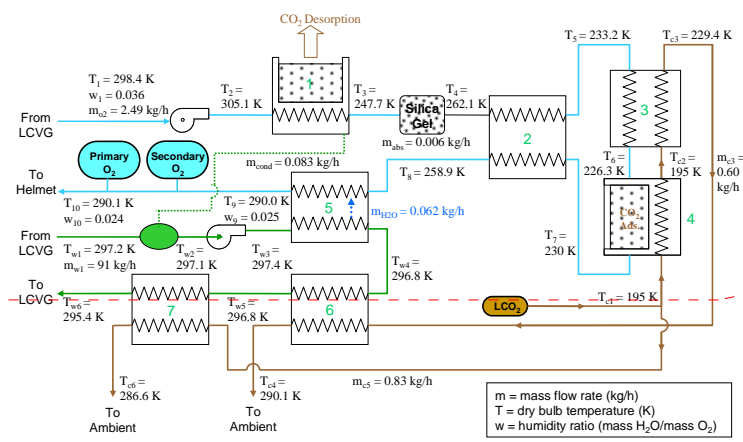

Comment: Is this suppose to be LCVG? Or is this the water loop?
Figure 14: Detailed results for Mars nominal environment, $300 \mathrm{~W}$ average metabolic rate

To determine the worst-case requirements on the heating system, an additional analysis was performed to assess the battery requirement for 100 minutes of electric heating at a metabolic rate of $100 \mathrm{~W}$ in a cold environment. Results are shown in Figure 15. As it turns out, for these conditions and assumed architecture, the heat generated by the water adsorption in the desiccant provides enough heat to eliminate the need for electric heating. An explanation follows. 


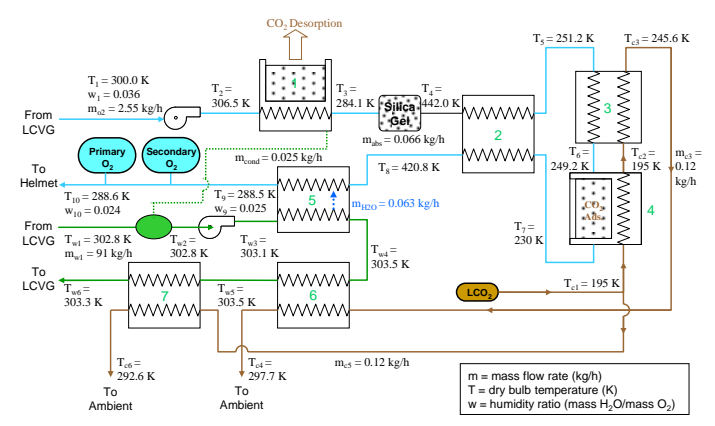

Figure 15: Detailed results for Mars cold environment, $100 \mathrm{~W}$ average metabolic rate

A user's $\mathrm{CO}_{2}$ generation rate decreases as metabolic rate decreases. Assuming the MTSA cycle is fixed, the amount of $\mathrm{CO}_{2}$ collected in the adsorbing bed will also decrease. Thus, during desorb mode, less energy is required to desorb the $\mathrm{CO}_{2}$. As less energy is consumed by the decreased amount of desorbing $\mathrm{CO}_{2}$, the bed will warm more quickly leaving the bed at higher temperatures during the remaining portion of the cycle and impeding condensation. Also, a warmer bed influences a warmer gas exhaust temperature.

The decrease in water condensation in the condensing ice heat exchanger drives an increase in the desiccant size. With the increase in water to be adsorbed, the heat released during water adsorption increases significantly. Subsequently, the ventilation loop gas temperature at the desiccant outlet increases to excessive temperatures (compare $262 \mathrm{~K}$ to $442 \mathrm{~K}$ ).

The heat is transferred to the ventilation gas returning to the user via the ventilation loop recuperative heat exchanger (2). As this result is too hot for entry into the helmet, the returning ventilation gas is cooled by the liquid water loop through heat exchanger 5 . This raises the temperature of the water before delivery to the LCVG such that heaters are not required.

The results of this case are being used to insure that the desiccant bed is appropriately sized to handle not only the cold conditions at the average metabolic rate of $300 \mathrm{~W}$, but also the 100 minutes at $100 \mathrm{~W}$. Since the amount of water processed by the desiccant increases as the metabolic rate decreases, this $100 \mathrm{~W}$ metabolic rate period places a greater-than-average demand on the desiccant, and therefore its sizing.

To avoid excessive desiccant bed size and ventilation gas temperatures, alternative architectures are being considered. One idea is to use a bypass valve where the ventilation gas bypasses the adsorbent beds at low metabolic rates. Control of the valve would depend on $\mathrm{CO} 2$ partial pressures of which up to $7.6 \mathrm{~mm} \mathrm{Hg}(1.0$ $\mathrm{kPa}$ ) are allowed for metabolic rates up to and including $470 \mathrm{~W}$ (1600 Btu/hr) for one hour. Another idea is to use a Nafion ${ }^{\circledR}$ membrane as a recuperative heat exchanger. As the only means of humidity control, sizing suggests the membrane area required is prohibitive in a PLSS. However, the area will be reduced when coupled with the condensing ice heat exchanger.

\section{CONCLUSION}

DEMONSTRATOR TESTING -Testing was performed with the pre-existing test bed and Demonstrator, a piece of hardware originally used to demonstrate the MTSA concept and feasibility. A humidifier subsystem was added to the test bed to simulate moisture in a ventilation loop. Insulation was added to the Demonstrator to better simulate modeling. Full MTSA cycles were simulated to set up proper conditions for evaluating performance during adsorbent regeneration (desorb mode).

Analysis of data shows that insulating the Demonstrator enables the adsorbent to achieve a lower temperature during cooling with less temperature variation. However, the addition of insulation did not significantly change the adsorbent warming time. Further, analysis of data collected during desorb testing with moist ventilation gas shows that the condensation/icing of water did not significantly influence the warming time either. In both dry and moist test cases, the ventilation gas inlet temperature is the dominant variable in determining the warming time.

During adsorbent regeneration using moist ventilation gas, water accumulation was observed inside the external heat exchanger at adsorbent casing temperatures below $279 \mathrm{~K}$. As temperatures increased to $285 \mathrm{~K}$, accumulation ceased. At temperatures above this, the external heat exchanger acted as a humidifier as condensed water began to increase the humidity of the ventilation gas. As the average adsorbent temperature achieved its $280 \mathrm{~K}$ set point for regeneration, the casing temperature was $289 \mathrm{~K}$. It can be inferred from this data that if the casing material temperature was near that of the adsorbent temperature, re-humidification can be avoided.

These observations stress the importance of maintaining uniform temperature distributions within the heat exchanger as well as minimizing the temperature variations between the adsorbent and heat exchanger materials.

While the impact of adding moisture to the ventilation gas was small in regards to the thermal response of the Demonstrator, it proved significant in terms of operation. The moisture in the ventilation gas condensed in the Demonstrator and appeared to form ice layers that persisted past the end of the warming cycle. This is a significant concern as repeated cycling of moist operations resulted in Demonstrator over pressurization and an aborted test. Any design using moist ventilation gas must include ice and moisture rejection as a technical requirement. 
ADSORBENT MODELING - A model built using Thermal Desktop ${ }^{\circledR}$ software of an adsorbent during regeneration at MTSA operating conditions has been calibrated. Model results match well temperature data collected from adsorbent beds regenerated after being loaded to different $\mathrm{CO}_{2}$ levels.

The final model setup utilized a $\mathrm{Cp}$ of $900 \mathrm{~J} / \mathrm{kg}-\mathrm{K}$ for the adsorbent, the actual $\mathrm{Cp}$ for the adsorbent material. It was found that the effective $\mathrm{Cp}$ originally derived to capture the impact of the energy from $\mathrm{CO}_{2}$ desorption was originally over estimated. Thus, the current model does not explicitly account for the heat of desorption of the $\mathrm{CO}_{2}$. The fact that temperature data related to corresponding model nodes vary similarly for each test, which had different levels of $\mathrm{CO}_{2}$ adsorbed, indicates that modeling the $\mathrm{CO}_{2}$ heat of desorption in the Demonstrator may not be significant.

MTSA SYSTEM THERMAL MODEL \& PLSS IMPACT A thermal model has been built to simulate a MTSA system in a PLSS. This model has been incorporated in EVAS_SAT for future MTSA PLSS sizing evaluations.

Model results demonstrate a MTSA system is realizable. An interesting result of the study was the potential for the MTSA adsorbent bed to warm too quickly during low metabolic rates and stress supporting dehumidification hardware. Final adsorbent bed mass (both of the adsorbent and the casing materials) will influence this effect. As the adsorbent bed/heat exchanger design is refined, this analysis should be reviewed. Also, as architectures for employing MTSA are studied, a Nafion $\circledast$ membrane dryer and a bypass valve should be considered as alternatives to a desiccant bed.

\section{ACKNOWLEDGMENTS}

Paragon gratefully acknowledges funding for this work from NASA Johnson Space Center under Contract NNJ06HA98C.

\section{REFERENCES}

1. C. Iacomini, MacCallum, T., Morin, T., Straub-Lopez, K., and Paul, H. L., "Martian Liquid $\mathrm{CO}_{2}$ and Metabolic Heat Regenerated Temperature Swing Adsorption for Portable Life Support Systems", Space Technology and Applications International Forum (STAIF) 2007, Albuquerque, NM, February $11-15,2007$.

2. Iacomini, C. S., Powers, A., Bower, C., StraubLopez, K., Anderson, G., MacCallum, T., and Paul, $\mathrm{H}$. L., "Metabolic heat regenerated Temperature Swing Adsorption for $\mathrm{CO}_{2}$ \& Heat Removal/Rejection in a Martian PLSS", 2007-013273, 2007.

3. Iacomini, C. S., Powers, A., Dunham, J., StraubLopez, K., Anderson, G., MacCallum, T., and Paul, H. L., "Demonstration of Metabolic Heat
Regenerated Temperature Swing Adsorption Technology", 2007-01-3274, 2007.

4. EVAS SAT reference will be added

Comment: Check how to reference

conference...(ICES07)

\section{DEFINITIONS, ACRONYMS, ABBREVIATIONS}

EVAS_SAT: Extravehicular Activity System Sizing Analysis Tool

LCVG: Liquid Cooling \& Ventilation Garment

$\mathrm{LCO}_{2}$ : Liquid carbon dioxide

MTSA: Metabolic Temperature Swing Adsorption

PLSS: Portable Life Support System

TC: Thermocouple 
